\title{
Effect of Alcohol Consumption Severity on Oral Health Status in Relation to Salivary Parameters, Smoking and Tooth Wear in Baghdad, Iraq
}

\author{
Ali Hadi Fahad ${ }^{1}$, Rafeef Ahmed Mohamed², Noor Mohammed Hadi Layedh² \\ ${ }^{l}$ Assistant Prof. of Preventive Dentistry, ${ }^{2}$ Assistant Lecture of Preventive Dentistry, Collage of Dentistry, \\ University of Kufa
}

\begin{abstract}
Background: Alcohol consumption not only affects the general health yet in addition the dental and gingival health of a person. Heavy drinkers are at high danger of creating dental caries, gingival health alteration and tooth disintegration. This condition brings about change in the salivary gland function. Alcohol abuse with smoking have diverse effects on oral health. This study presented to evaluate the effect of alcohol consumption severity on oral health in relation to salivary parameters, smoking and tooth wear in Baghdad, Iraq.
\end{abstract}

Materials and Method: One hundred and twenty 35-40 years old men with alcohol consumption selected randomly. Alcohol consumption individuals classified into three groups according to frequency of alcohol consumption: regular drinker (GA), frequent drinker (GB) and occasion drinker (GC). Each group consists of 40 individuals. Gingival (GI), calculus (CI) and dental caries (DMFT) indices were utilized to assess dental and gingival health for all individuals. Parameters of saliva including flow rate and $\mathrm{pH}$ assessed immediately. Tooth wear (TW) was estimated according to the presence or absence of dentine. Smoking was recorded directly from individual. The results of present study was dissected utilizing SPSS version 23.

Results: The median is higher in GA than GB and GC with highly significant difference between groups. For PII, median is higher in GC than other groups, but the mean rank is higher in GA than other groups (no significant difference). For both GI and CI, median and mean rank are higher in GA than others with significant difference between them. Salivary flow rate and $\mathrm{pH}$ means are higher in GC than other groups with highly significant differences regarding $\mathrm{pH}$. The high percentage of drinker with tooth wear was recorded in GA compared to other groups with significant difference. The median and mean rank are higher in smoking drinker than non-smoking drinkers with highly significant difference.

Conclusion: Dental caries, periodontal diseases, tooth wear and lower salivary $\mathrm{pH}$ were more presented in individuals with more frequent alcohol consumption. Alcohol drinking with smoking increase the occurrence of dental caries.

Keywords: Alcohol consumption; Regular drinker; DMFT; Tooth wear.

\section{Introduction}

Corresponding Author:

Ali Hadi Fahad

Assistant Prof. of Preventive Dentistry, Collage of

Dentistry, University of Kufa

e-mail: alih.fahad@uokufa.edu.iq
Alcohol drinking may be an expansive haul utilized to any drinking about it that bring about mental or physical wellbeing issues. Problems of alcohol occur as a result of excessive consumption of it that affect not just with individuals, at will their families, groups and culture in general. Utilizing of liquor can influence all 
component of body, yet uncommonly influences defense mechanism, liver, heart and nervous responses ${ }^{[1]}$. Alcohol drinking not only can affect the integrity of the whole body but also can affect the proper oral environment of a person ${ }^{[2,3]}$. It has been found that drunkards are at high danger of creating dental lesions, gingival impairment and may expose to the risk of oral cancer. Alcohol drinking whether in little or enormous sum can have huge influence on oral environment of a person in light of carelessness and may prompt various oral problems ${ }^{[4]}$.

In long term alcohol drinkers, generally the parotid glands may get enlargement. This issue is called sialadenosis and ordinarily connected with ethanol incitation ${ }^{[5,6]}$. Unsettling influences in the salivary glands function happened because of sialadenosis. Decrease in the salivary discharge along with decline in buffering limit along with less oral cleanliness may prompt more chance of dental caries and gingival impairment ${ }^{[7]}$. Other hindering components comprise of utilizing of sugared beverages and cariogenic food and liquor. The acidic idea of mixed drinks along with utilization of sugar rich food bring about creation of acids and cause diminish in salivary $\mathrm{pH}$ underneath basic level. Obsoletely, it might cause advancement of dental lesions. Also, liquor misuse may cause expanding in Blood Lead Levels (BLLs) in people and BLLs which is associated with dental lesions ${ }^{[8]}$.

An investigation got more caries activity among drunkards, likewise the heavy drinkers had more number of endodontically filled teeth in correlation non-heavy drinkers. Alcoholic drinkers had an extracted tooth three times more than the non-drinker for comparing ages ${ }^{[9]}$. Other research also found a positive relation between alcohol abuse and caries activity ${ }^{[10]}$.

Alcohol consumption can prompt periodontal impairment for various reasons involving: gingival tissue aggravation; less oral cleanliness propensities among incessant liquor consumers; improper dietary patterns causing nourishing inadequacies among interminable heavy drinkers causing alteration of defense mechanism to exposing destructive compounds; less salivary discharge from liquor misuse make the microbes and plaque develop on the grounds that they are not eliminated away by salivation; progression of diseases to more serious condition as a result of ignorance of early symptoms of gingival diseases may lead periodontal impairment ${ }^{[11,12]}$.
An increased risk of developing dental erosion occurs as a result of people addiction to alcohol consumption. This happened because of alcohol use that considered the potential for expanding the debasement rate components and by the immediate and roundabout ethanol impacts ${ }^{[13]}$. The palatal surfaces of maxillary teeth are the most generally influenced tooth surfaces because of erosion followed by the occlusal surfaces of posterior teeth while the lower teeth and buccal surfaces of the maxillary teeth are least influenced by erosion ${ }^{[14]}$. It also found that alcohol use in conjunction with smoking cause increasing in the occurrence of dental lesion for individuals. Tobacco and alcohol consumptions cause changes in oral microorganisms that may assume a basic part in the development and exaggeration of dental lesion ${ }^{[15]}$.

To the extent, no Iraqi investigation was led among individuals with alcohol consumption in Baghdad concerning the link between severity of alcohol consumption and dental caries, gingival diseases in relation to salivary parameters, smoking, and tooth wear. For all these clarification, this research was planned.

\section{Materials and Method}

One hundred and twenty 35-40 years old males with alcohol consumption from Baghdad City were included in this study. Individuals were selected randomly by making a special free offer at 4 alcohol stores ( 2 on the side of Karkh and 2 on the side of Al-Rusafa). This free offer includes doing a prophylaxis for an examination and a saliva sample collection which done in the private dental clinic last four months. Alcohol consumption individuals classified into three groups according to frequency of alcohol consumption ${ }^{[16]}$ :

1. Regular drinker (GA) (More than four a week), 2. Frequent drinker (GB) (One to four days a week) and 3. Occasion drinker (GC) (Less than three days a week Each group consists of 40 males. Gingival aggravation evaluated by utilizing gingival list (GI) of Löe and Silness ${ }^{[17]}$. Oral cleanliness status assessed by using Ramfjord calculus index $(\mathrm{CI})^{[18]}$, and plaque index (PII) from claiming Silness and Löe ${ }^{[19]}$. Caries experience for each drinkers recorded according to WHO criterion utilizing DMFT index ${ }^{[20]}$. To assess salivary parameters, every person was approached to plunk down and loosens up much as could be expected under the circumstances and solicited to chew a piece from 
Arabic gum for one minute before expectoration; for ten minutes, chewing was proceeded with a similar bit of gum and the assortment of salivation by spitting was finished within this time ${ }^{[21]}$. By dividing the absolute volume of saliva gathered in milliliter on the time of assortment in minute, flow rate of saliva was estimated. $\mathrm{pH}$ of saliva recorded by utilizing electronic $\mathrm{pH}$ meter.

According to the absence and present of dentine, tooth wear (TW) recorded was essentially dichotomized depending on the criterion of Bardsley et $\mathrm{al}^{[22]}$.

Selected parameters were analyzed by utilizing SPSS 23 version (Statistical Package for Social Sciences).

\section{Results}

Table 1 illustrates the median and mean rank values of DMFT index among drinkers groups with statistical significance. The median and mean rank are higher in GA than GB and GC with highly significant difference between groups (Kruskal Wallis value $=10.000$, $\mathrm{p}$-value $=0.007)$. Mann-Whitney test for DMFT index shows highly significant difference between GA and GC (Mann-Whitney value $=487.000, \mathrm{Z}=-3.050, \mathrm{p}$-value $=$ 0.002 ), and significant difference between GB and GC (Mann-Whitney value $=579.500, \mathrm{Z}=-2.150, \mathrm{p}$-value $=$ 0.032 ), while no significant difference between GA and GB.

Median and mean rank of PII, GI and CI among drinker groups are demonstrated in Table 2. For PII, median is higher in GC (1.73) than other groups, but the mean rank is higher in GA (69.03) than other groups (no significant difference). For both GI and CI, median $(1.71,1.67$ respectively) and mean rank $(74.74,72.39)$ are higher in GA than others with significant difference between them (Kruskal Wallis value $=11.214,8.087$, $\mathrm{p}$-value $=0.004,0.018$ respectively). Mann-Whitney test for GI and CI record significant difference between (GA and GB), also between (GA and GC), while no significant difference between GB and GC.

Table 3 records mean values of stimulated salivary flow rate and $\mathrm{pH}$ among drinker groups with statistical differences. A higher value of SFR was found among GC $(1.55 \mathrm{ml} / \mathrm{min})$ compared to other groups with no significant differences between them, but t-test shows significant difference between GA and GC ( $\mathrm{p}$-value = 0.017 , t-value $=-2.438, \mathrm{df}=78$ ). For salivary $\mathrm{pH}$, also mean is higher in GC (6.66) than other groups with highly significant differences ( $p$-value $=0.002$, F-value $=2.903, \mathrm{df}=2$ ). Using $\mathrm{t}$-test highly significant difference was concluded between GA and GC (p-value $=0.001$, $\mathrm{t}$-value $=-3.455, \mathrm{df}=78)$, also significant difference was recorded between $\mathrm{GB}$ and $\mathrm{GC}(\mathrm{p}$-value $=0.020$, $\mathrm{t}$-value $=-2.369$, df $=78$ ).

The distribution of drinkers with tooth wear among drinker groups with statistical difference is presented in Table 4. The high percentage of drinker with tooth wear was recorded in GA (42.5\%) compared to other groups with significant difference $\left(\mathrm{p}\right.$-value $=0.039, \chi^{2}=6.48$, $\mathrm{df}=2)$.

Table 5 shows the distribution of smoking drinkers among drinker groups with statistical difference. The high percentage of smoking drinker was shown in GA $(42.5 \%)$ with no significant difference between drinker groups.

Table 6 concludes median and mean rank of DMFT index among smoking and non-smoking drinkers with statistical significant. The median (13) and mean rank (65.88) are higher in smoking drinker than non-smoking drinkers with highly significant difference (MannWhitney value $=550.500, Z=-3.626, \mathrm{p}$-value $<0.001)$.

Table 1: Mean rank and median of DMFT among drinker groups with statistical significances

\begin{tabular}{|l|l|c|c|c|c|}
\hline & Drinker group & Median & Mean Rank & Kruskal Wallis Test (Chi square) & p-value \\
\hline \multirow{3}{*}{ DMFT } & GA & 14 & 70.88 & & \multirow{2}{*}{0.000} \\
\cline { 2 - 5 } & GB & 13 & 63.46 & & $0.007 * *$ \\
\cline { 2 - 5 } & GC & 12 & 47.16 & & \\
\hline
\end{tabular}


Table 2: Mean rank and median of gingival, calculus and plaque indices among drinker groupswith statistical differences.

\begin{tabular}{|c|c|c|c|c|c|}
\hline Variables & Drinker group & Median & Mean Rank & Kruskal Wallis Test (Chi square) & p-value \\
\hline \multirow{3}{*}{ PI } & GA & 1.71 & 69.03 & \multirow{3}{*}{3.63} & \multirow{3}{*}{0.163} \\
\hline & GB & 1.69 & 55.74 & & \\
\hline & GC & 1.73 & 56.74 & & \\
\hline \multirow{3}{*}{ GI } & GA & 1.71 & 74.74 & \multirow{3}{*}{11.214} & \multirow{3}{*}{$0.004 * *$} \\
\hline & GB & 1.61 & 57.51 & & \\
\hline & $\mathrm{GC}$ & 1.50 & 49.25 & & \\
\hline \multirow{3}{*}{ CI } & GA & 1.67 & 72.39 & \multirow{3}{*}{8.087} & \multirow{3}{*}{$0.018^{*}$} \\
\hline & GB & 1.49 & 58.56 & & \\
\hline & GC & 1.33 & 50.55 & & \\
\hline
\end{tabular}

Table 3: Mean values of salivary flow rate and $\mathrm{pH}$ among drinker with statistical differences.

\begin{tabular}{|c|c|c|c|c|c|c|}
\hline \multirow{2}{*}{ Variables } & \multirow{2}{*}{ Groups } & \multirow{2}{*}{ No. } & \multirow{2}{*}{$($ Mean \pm SD $)$} & \multicolumn{3}{|c|}{ Statistical difference } \\
\hline & & & & F-value & df & p-value \\
\hline \multirow{3}{*}{$\mathrm{pH}$} & GA & 40 & $6.21 \pm 0.093$ & \multirow{3}{*}{6.34} & \multirow{3}{*}{2} & \multirow{3}{*}{$0.002 * *$} \\
\hline & GB & 40 & $6.35 \pm 0.564$ & & & \\
\hline & GC & 40 & $6.66 \pm 0.578$ & & & \\
\hline \multirow{3}{*}{$\begin{array}{l}\text { Salivary flow } \\
\text { rate }(\mathrm{ml} / \mathrm{min})\end{array}$} & GA & 40 & $1.30 \pm 0.448$ & \multirow{3}{*}{2.903} & \multirow{3}{*}{2} & \multirow{3}{*}{0.059} \\
\hline & GB & 40 & $1.40 \pm 0.493$ & & & \\
\hline & $\mathrm{GC}$ & 40 & $1.55 \pm 0.478$ & & & \\
\hline
\end{tabular}

Table 4: The distribution of drinkers with tooth wear among drinker groups with statistical differences.

\begin{tabular}{|c|c|c|c|c|c|c|}
\hline \multirow{2}{*}{ Groups } & \multirow{2}{*}{ No. } & \multicolumn{2}{|c|}{ No. of drinkers with tooth wear } & \multicolumn{3}{|c|}{ Statistical difference } \\
\hline & & No. & $\%$ & Chi-square & df & p-value \\
\hline GA & 40 & 17 & 42.5 & \multirow{3}{*}{6.48} & \multirow{3}{*}{2} & \multirow{3}{*}{0.039} \\
\hline GB & 40 & 10 & 25 & & & \\
\hline GC & 40 & 7 & 17.5 & & & \\
\hline
\end{tabular}

Table 5: the distribution of smoking drinkers among drinker groups with statistical difference.

\begin{tabular}{|l|c|c|c|c|c|c|}
\hline \multirow{2}{*}{ Groups } & \multirow{2}{*}{ No. } & \multicolumn{2}{|c|}{ No. of smoking drinkers } & \multicolumn{3}{|c|}{ Statistical difference } \\
\cline { 3 - 6 } & & No. & \% & Chi-square & df & \multirow{2}{*}{ p-value } \\
\hline GA & 40 & 5 & 42.5 & 2.12 & 2 & 0.347 \\
\hline GB & 40 & 7 & 25 & 17.5 & & \\
\hline
\end{tabular}

Table 6: Mean rank and median of DMFT index among smoking and non-smoking drinkers with statistical significant.

\begin{tabular}{|l|c|c|c|c|c|c|}
\hline \multirow{2}{*}{ Groups } & \multirow{2}{*}{ No. } & \multicolumn{2}{|c|}{ DMFT } & \multicolumn{2}{|c|}{ Statistical difference } \\
\cline { 3 - 6 } & & Median & Mean Rank & Mann-Whitney U & z-value & p-value \\
\hline Smoking Drinkers & 98 & 13 & 65.88 & \multirow{2}{*}{550.500} & -3.626 & $<0.001 * *$ \\
\hline Non-Smoking Drinkers & 22 & 11 & 36.52 & & & \multirow{2}{*}{} \\
\hline
\end{tabular}




\section{Discussions}

The problems of sever alcoholism have been linked with alteration in oral tissues and neglecting of oral health. Many researches recorded the association

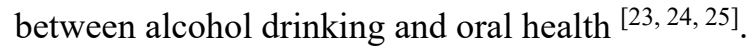

This study showed that dental caries experience was higher in regular drinker than other groups. The amount of alcohol taken and prevalence of dental caries are associated positively. This finding is agreed with many studies $^{[11,26,27,28,29]}$. Alcohol drinkers are known to have bad oral hygiene. It was found that alcohol user had incorrect personal and professional health care and also had dry mouth at night. Also, the consumption of high amount of refined carbohydrates may be the cause for high caries experience noted among them ${ }^{[27]}$.

Periodontal disease represent many problems that can be ranged from simple inflammation of the gingiva to more serious one. Usually, it started in the mouth with bacterial growth along with building of plaque on the gingiva. This can be lead to inflammation or even a severe infection. Some kinds of gingival disease may be also become worse by alcohol consumption. It has been found in this study that mean rank of PII, GI, CI are higher in GA group than others and this is may be due to irritation to the gingival tissue. This result is in line with many studies ${ }^{[11,12,13,30,31]}$. Also, the individuals who are involved in alcohol user tend to have a bad dental hygiene habits. This result in making them more susceptible to such problems. The alcoholics persons tend to eat poorly, and this may cause nutritional deficiencies leading to all kinds of a disease to happen. Deficiencies in the diet can also make lowering in effectiveness of the immune response and so increasing the developing of gingiva disease. The persons who drink alcohol will often display the early symptoms of gingival disease which mean that easily treatable case of gingivitis will be progressed to a more serious one that involved permanent damage to the gums and teeth. In general, a poor oral health and bad dental care were associated with the periodontal problems in alcohol abusers ${ }^{[32]}$.

It has been found in this study that the salivary flow rate is higher in GC group than other groups and this result agree with other studies ${ }^{[33,34]}$. The reason for these results that the parotid gland become more swollen with excessive drinking (sialadenitis) that lead to alteration in the excretion and metabolism of the salivary glands ${ }^{[35]}$.

The current study concludes, the high percentage of drinker with tooth wear was recorded in GA compared to other groups and this result similar to some studies $[13,28,29]$. The prolonged and regular abuse of acidic drinks as alcohol making the oral cavity more acidic in nature. This acidification result in dissolving the enamel surface and will make teeth surfaces more susceptible to a mechanical damage as tooth-brushing. Frequent vomiting occurs as a lowering in esophageal sphincter relaxes under the effect of alcohol. Enamel erosion occurred as a result of entering the acidic content of the stomach to the mouth (vomiting). This acidification along with reduction in salivary secretion and reduction in buffering capacity lead to raising the risk of enamel erosion ${ }^{[13,36]}$.

It has been recorded that smoking and alcohol consumption make adverse effects on individual as a general and oral health. In this study, the higher percentage of smoking was found among the GA group. The mean rank and median of DMFT are higher in smoking drinker than non-smoking drinkers with highly significant difference. There is a positive association smoking and alcohol abuse ${ }^{[37,38]}$. Several mechanisms may lead to the relation between smoking and alcohol drinking, involving the genes which include in a regulating neurotransmitters, cross-sensitization and cross-tolerance, and common psychological and social factors ${ }^{[39,40]}$. The high DMFT founded among smokers with alcohol abuse reflects the physical improper of oral hygiene measures and variation in oral micro-flora ${ }^{[15]}$.

Conflict of Interest: We declare that there is conflict of interest

Ethical Approval: the research approved by scientific and ethical committee at our department

Source of Funding: the research funded by the authors only.

\section{References}

1. American Psychiatric Association (2013). Diagnostic and statistical manual of mental disorders: DSM5 (5 Ed.). Washington, DC: American Psychiatric Association. pp. 490-97.

2. Alcohol Use Disorder: A Comparison between DSMIV and DSM-5. November 2013. Archived from the original on 18 May 2015.Retrieved 9 May 2015.

3. Khairnar MR, Wadgave U, Khairnar SM. Effect of Alcoholism on Oral Health: A Review. J Alcohol Drug Depend 2017; 5(3): 1-4. 
4. Bode C, Bode JC. Alcohol's role in gastrointestinal tract disorders. Alcohol Health Res World 1997; 21: 76-83.

5. Mandel L, Hamele-Bena D. Alcoholic parotid sialadenosis. J Am Dent Assoc 1997; 128: 14111415.

6. Guggenheimer J, Close JM, Eghtesad B. Sialadenosis in Patients with Advanced Liver Disease. Head Neck Pathol 2009; 3: 100-105.

7. Chilla R. Sialadenosis of the salivary glands of the head. Studies on the physiology and pathophysiology of parotid secretion. Adv Otorhinolaryngol 1981; 26: 1-38.

8. Chang WH, Yang YH, Liou SH, Liu CW, Chen CY. Effects of mixology courses and blood lead levels on dental caries among students. Commun Dent Oral Epidemiol 2010; 38: 222-227.

9. Dunkley RP, Carson RM. Dental requirements of the hospitalized alcoholic patient. J Am Dent Assoc 1968; 76: 800-803.

10. Marc Niquille M, Burnand B, Macnenat P, Paccaud F, Yersin B. Dental disease among alcoholic individuals: a comparative study of hospitalized patients. J Gen Intern Med 1993; 8: 470-475.

11. Harris C, Warnakulasuriya KA, Gelbier S, Johnson NW, Peters TJ. Oral and dental health in alcohol misusing patients. Alcoholism 1997; 21: 17071709.

12. Tezal M, Grossi SG, Ho AW, Genco RJ. The effect of alcohol consumption on periodontal disease. $\mathrm{J}$ Periodontol 2001; 72: 183-189.

13. Mahesh R K, Umesh W, Sonam M K. Effect of Alcoholism on Oral Health: A Review. Alcohol Drug Depend 2017; 5: 3.

14. Peycheva K, Boteva E. Effect of alcohol to oral health. Acta Medica Bulgarica 2016; 43: 71-77.

15. Thavarajah R, Vidya KM, Elizabeth J, Anita R, Shanthi R, Umadevi K R, Ranganathan K. Tooth decay in alcohol and tobacco abusers. Journal of Oral and Maxillofacial Pathology 2011; 15: 1.

16. Baker S P, Braver E R, Chen L-H, Li G, Williams A F. Drinking histories of fatally injured drivers. Injury Prevention 2002; 8: 221-226.

17. Löe $H$ and Silness J. Periodontal disease in pregnancy. Acta Odontol Scand 1963; 21: 533551.

18. Ramfjord SP. Indices for prevalence and incidence of periodontal disease. J Perio 1959; 30: 51-59.

19. Silness J, Löe H. Periodontal disease in pregnancy. Correlation between oral hygiene and periodontal condition. Acta Odontol Scand. 1964; 22: 121-135.

20. WHO. Oral health surveys basic method. 4th ed. World health organization. Geneva, Switzerland 1997.

21. Ali R. Odontometric measurements and salivary cortisol among low birth weight 5 years old kindergarten children in relation to dental caries. Master thesis, College of Dentistry, University of Baghdad, (2013).

22. Francisco Javier López-Frías, Lizett CastellanosCosano, Jenifer Martín-González, José María Llamas Carreras, Juan José Segura-Egea. Clinical measurement of tooth wear: Tooth wear indices. J ClinExp Dent. 2012; 4(1):e48-53.

23. Pereira ELA, Sena EP, Oliveira IR. Farmacologia do álcooletílico. Tratamentofarmacológico do alcoolismo. In: Silva P. Farmacologia. $6^{\text {a }}$ ed. Rio de Janeiro: Guanabara Koogan; 2002; 38: 351-7.

24. Enberg N, Wolf J, Ainamo A, Alho H, Heinala P, Lenander-Lumikari M. Dental diseases and loss of teeth in a group of Finnish alcoholics: a radiological study. ActaOdontol Scand. 2001; 59(6): 341-7

25. Hornecker E, Muuss T, Ehrenreich H, Mausberg RF. A pilot study on the oral conditions of severely alcohol addicted persons. J Contemp Dent Pract. 2003; 4(2): 51-9.

26. Kakarla P, Kudlur S, Chandra V, Krishna RVS, Srinivasulu G. Impact of Alcohol Dependency on Oral Health - A Cross-sectional Comparative Study. J ClinDiagn Res. 2017; 11(6): ZC43-ZC46.

27. Dasanayake AP, Warnakulasuriya S, Harris CK, Cooper DJ, Peters TJ. Tooth decay in alcohol abusers compared to alcohol and drug abusers. Int $\mathrm{J}$ Dent. 2010: 1-6.

28. Peycheva K, Boteva E. Effect of alcohol to oral health. ActaMedicaBulgarica 2016; 1: 71-77.

29. Grocock R. The relevance of alcohol to dental practice. BDJ 2015: 11-15.

30. Lages EJ, Costa FO, Cortelli SC, Cortelli JR, Cota LO. Alcohol Consumption and Periodontitis: Quantification of Periodontal Pathogens and Cytokines. J Periodontol 2015; 86: 1058-1068.

31. Ali DA, Brown RS, Rodriguez LO, Moody EL, Nasr MF. Dental erosion caused by silent 
gastroesophageal reflux disease. J Am Dent Assoc 2002; 133: 734-737.

32. Novacek G, Plachetzky U, Potzi R. Dental and periodontal disease in patients with cirrhosis role of etiology of liver disease. J Hepatol.1995; 22: $576-8$.

33. Dutta SK, Orestes M, Vengulekur S, Kwo P. Ethanol and human saliva: effect of chronic alcoholism on flow rate, composition, and epidermal growth factor. Am J Gastroenterol. 1992; 87(3):350-4.

34. Walter D, Tanja T D, Marina K, Stjepanka L. Caries prevalence in chronic alcoholics and the relationship to salivary flow rate and $\mathrm{pH}$. Cent Eur J Public Health 2013; 21 (1): 43-47.

35. Guggenheimer J, Close JM, Eghtesad B. Sialadenosis in Patients with Advanced Liver Disease. Head Neck Pathol 2009; 3: 100-105.

36. Rohan S, Kriti G. Oral Health Negligence in Alcohol Consumers: A Review. Adv Med Dent Scie Res 2018; 6(8): 49-52.
37. Friedman G. D., Tekawa I., Klatsky A. L., Sidney S., Armstrong M. A. Alcohol drinking and cigarette smoking: an exploration of the association in middle-aged men and women. Drug Alcohol Depend 1991; 27: 283-290.

38. Kaner E. F., Beyer F., Dickinson H., Pienaar E., Campbell F., Schlesinger C. et al. Effectiveness of brief alcohol interventions in primary care populations. Cochrane Database Syst Rev 2007; Issue 2. Art.

39. Taylor G., McNeill A., Girling A., Farley A., Lindson-Hawley N., Aveyard P. Change in mental health after smoking cessation: systematic review and meta-analysis. BMJ 2014; 348: g1151.

40. World Health Organization. Global status report on alcohol and health. Geneva, Switzerland: World Health Organization; 2014. 